\title{
A HAIRY SITUATION: CHILD PROTECTION WORKERS EXPERIENCES PROVIDING HAIR CARE TO AFRICAN CANADIAN CHILDREN IN CARE
}

by

Chantal Gray, BSW, York University, 2015

\author{
An MRP \\ Presented to Ryerson University \\ In partial fulfillment of the \\ requirements for the degree of \\ Master of Social Work \\ in the Program of \\ Social Work
}

Toronto, Ontario, Canada, 2017

(C) Chantal Gray 2017 


\section{AUTHOR'S DECLARATION FOR ELECTRONIC SUBMISSION OF A MRP}

I hereby declare that I am the sole author of this MRP. This is a true copy of the MRP, including any required final revisions.

I authorize Ryerson University to lend this MRP to other institutions or individuals for the purpose of scholarly research.

I further authorize Ryerson University to reproduce this MRP by photocopying or by other means, in total or in part, at the request of other institutions or individuals for the purpose of scholarly research.

I understand that my MRP may be made electronically available to the public. 


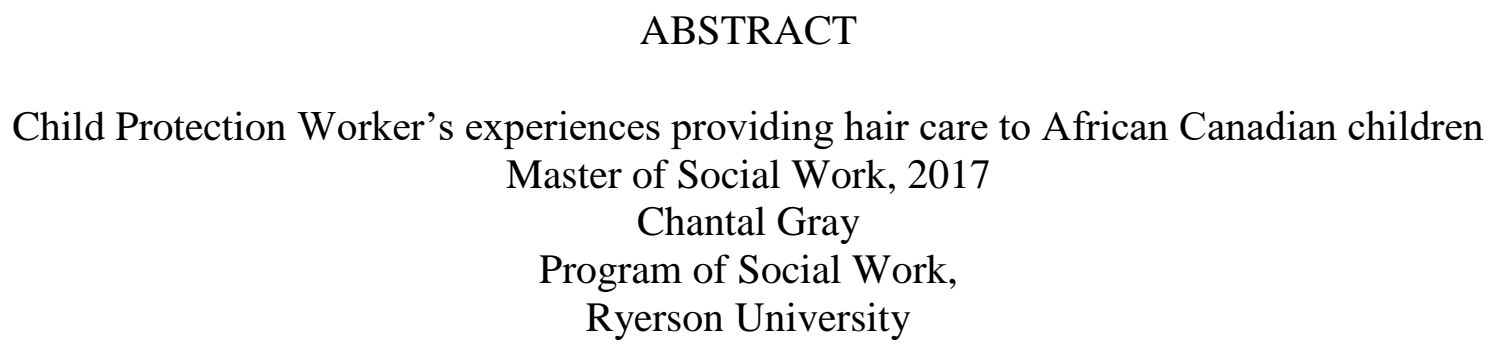

This research explores the experiences of Child Protection Workers regarding Black youth hair maintenance while in care, as hair is a significant identity marker for Black children. Additionally, it is important to understand the rights and responsibilities of the child protection workers, foster parents, biological parents and outside paid resources, as they all play different, but vital roles in a child's life. The training that child welfare agencies provide and community resources will also be discussed. I began the study by providing an overview of the literature on the topics of Black hair and responsibilities of the child welfare agencies. A critical race theory framework will deepen the understanding of racism intertwined with hair; as well as exploring terms such as organization, whiteness and cultural competency. A narrative approach was used as the methodology and detailed within the findings section. The study found that there was inconsistency within the agency together with lack of resources to be used in the community. 


\section{ACKNOWLEDGEMENTS}

I would like to thank the three participants for being a part of this research. I am thankful that they were able to provide insight into the child welfare system and would also like to thank, my MRP supervisor, Dr. Susan Preston for providing me with guidance throughout the process.

To my family, who have been encouraging and praying for me as well as my friends, who have been supportive and provided a listening ear when needed. 


\section{TABLE OF CONTENTS}

Chapter I: Introduction $\quad 1$

Chapter II: Theoretical Framework

$\begin{array}{ll}\text { Chapter III: Literature Review } & 13\end{array}$

Chapter IV: Methodology 25

$\begin{array}{ll}\text { Chapter V: Findings } & 30\end{array}$

$\begin{array}{ll}\text { Chapter VI: Discussion } & 38\end{array}$

Chapter VII: Implications and Conclusion 53

$\begin{array}{lr}\text { Appendices } & 58\end{array}$

$\begin{array}{ll}\text { References } & 64\end{array}$ 


\section{LIST OF APPENDICES}

$\begin{array}{lr}\text { Appendix A - Consent form } & 58\end{array}$

$\begin{array}{ll}\text { Appendix B - Interview guide } & 61\end{array}$

Appendix C - Research flyer $\quad 62$

Appendix D - Research email 63 


\section{Chapter I: Introduction}

"Hair is at the heart of many Black women's sense of who they are..." (Prince, 2009, p. 16). As a result, Black hair is a significant identity marker or breaker, which sets the standard by which Black individuals aspire to measure up to society's established sense of what constitutes beautiful hair. Hair affects and defines Black people on an individual as well as systemic level. Black society acknowledges beautiful hair from birth, with talk of "what a lovely head of hair" or "she is going to have really good, long hair," to "this one will have to be permed early". The issue that will be addressed in this research study is how workers within the child welfare field provide hair care services for Black children in care. There has been a recent natural hair movement within North America that encourages Black youth to embrace their crown. Natural hair is a term that is used to describe hair that has not been affected by chemicals or heat (EllisHervey et al., 2016). As a result, it will be helpful to understand how Black youth in care hair is cared for by child welfare protection services. The term 'Black' is defined as a 'politically unifying terminology for...who were not necessarily of African ancestry” (Wane et al., 2002, p. 14). While African, is "embraced by Diasporic African peoples to more accurately reflect their cultural and political affinity to the continent" (Wane et al., 2002, p. 14).

There is an over-representation of Black children in the care of child protection services due to different circumstances, including discrimination based on race (Chand, 2000). Race is described as "an arbitrary classification of populations conceived in Europe, using actual or assumed biologically determined traits (i.e., skin color and other physical features) to place populations of the world into hierarchical order" (Baines, 2003, p. 87). Hence, the themes that will be focused on are the historic discrimination against Black hair, dominant beauty standards and the challenges Black youth face within the child welfare system. To understand the context 
of hair, a historical context is necessary. Additionally, it is important to understand how historical practices have been internalized. Henceforth, the theoretical framework, literature review, and methodology will be explored, providing a deeper understanding about child protection workers' experiences in providing hair care for Black youth and children in care.

This research stems from the direct experiences I encountered, having worked within a group and foster home setting. On one occasion, a foster parent had asked me for recommendations on how to best care for a child's hair, as the child was biracial (Black and Filipino). As a Black female who wears her hair naturally, she thought that I could assist in sharing styles and products to help with the child's hair to ensure that it was healthy, grows long and is declared beautiful. I do understand the experiences and challenges associated with Black and natural hair maintenance. I too have experienced systemic discrimination due to my decision to establish my own notion of what constitutes beautiful hair. In addition, I have experienced both positive and negative comments about my hair from Black, white, and other racialized individuals. I eventually began to dislike the chemical processing of my hair, deciding instead to go on a journey into my 'natural' Black hair state. It is rather interesting trying to navigate my way into and within a society that privileges white beauty standards, with hair that does not fit in. Furthermore, I have become accustomed to my hair being a spectacle with people wanting to touch it and asking "is it yours? Why don't you process it, it would look so good!". It is from these standpoint experiences that I decided to research and assess how child protection workers' roles of power and perspectives on Black hair and beauty impact children's identity and hair, as they assume the role of 'guardian' or 'parent' while children are in their care.

This issue of Black hair has dominated the forefront of many media sites. It is discussed in newspaper articles with headlines such as 'Black foster youth reclaim their voice' in Metro 
Canada (2016) and 'Taking steps to help Black youth in CAS' in the Toronto Star (2014). These articles discuss the systemic racism within the child welfare system, which includes issues about hair styling and the Black youth. The recent dates of these news articles indicate that Black youth and their hair is still a current, relevant and debatable issue as Black individuals struggle to establish or decide on their accepted identity. The hope is that this research will continue the discussion as well as giving new insights, around Black youth and their identity within the child welfare system.

This research highlights that child protection worker's are in a position of power, in contrast to the clients they are supporting which are Black children who experience power over them by adults who also may be of a different racial identity (such as white Child Protection Workers). It is the expectation that the findings and analyses from this research will contribute to the education of individuals who work with Black youth in various social service settings, to lessen the sometimes negative experiences and stereotypes associated with hair styling for Black youth in care. Having had profound interest in this topic, I will continue to offer necessary and pertinent reflections as it is important within organizations such as child welfare, that critical reflections are tied into one's practice. Critical reflection is important as it allows workers and supervisors to "[question] the ways in which one's social location impacts their impressions of a case", as well as "a self-awareness of the ways bias and stereotyping skew decision making" (Lietz, 2008, p. 33). Through continued reflections I will ensure that I am monitoring my own practice daily, in order to minimize margins of error, as well as to ensure that my clients are receiving effective services. This practice reflects anti-oppression theorists' view that "social workers [should] constantly reflect on ways in which social structures associated with capitalism, 
patriarchy and imperialism contribute to, and interact with, the personal and cultural levels of oppression” (Healy, 2005, p. 180).

The following chapters that will be discussed in this paper include: the theoretical frameworks, literature review and methodology that will shape the research, the findings, and the discussion based on the analysis of the findings. The theoretical frameworks and concepts that will be discussed include critical race theory (CRT), organization systems and cultural competency. The literature review is a detailed evaluation of the research pertaining to the hair industry and Black children in care. The methodology chapter describes the approach and strategies to accomplish the research. The findings section will provide first-hand experiences of child protection workers in the field, which is finally followed by a detailed discussion of the literature explored in the findings. 


\section{Chapter II: Theoretical Framework}

The theoretical framework that will be used to inform this research is the critical race theory (CRT). In addition, the concepts of organization systems and cultural competency will be further discussed to provide context to the structures of child welfare and Black culture. The theoretical framework shapes how the research is viewed. CRT was selected as the theoretical framework as it acknowledges that inequality between Black and white is a systemic issue that occurs daily within society (Constance-Huggins, 2012). Additionally, CRT can help to provide transformative action and highlight the impact of racism (Constance-Huggins, 2012).

CRT was developed in the 1970's through the work of Derrick Bell and Alan Freeman within the United States (Constance-Huggins, 2012). It developed out of the Civil Rights Movements, due to frustration with the ways that the Civil Rights Movements was inconsistent and maintained the current structures of class (Constance-Huggins, 2012). Bell and his associates were perturbed about the positivist and liberal legal discourses of it (Constance-Huggins, 2012). They also found that critical legal studies were limited in critiquing racial issues and excluded oppressed voices. Although CRT was developed from law and legal studies, there is now more focus on racism within society. Constance-Huggins (2012) argued that CRT is guided by six principles, firstly, that racism is experienced daily by marginalized people. This can be experienced due to physical differences such as hair. "CRT suggests that the functions and effects of racism are often invisible to people with racial privileges" (Constance-Huggins, 2012, p. 7). It has been my observation that sometimes this can be seen between white workers in the system, and the Black children with whom they work. Thobani (2007) acknowledges that Canada has a facade of valuing diversity and promotes this through a multicultural guise. 
The second tenet of CRT focuses on race as a social construction and systemic issue that characterizes people based on physical features (Constance-Huggins, 2012) such as skin colour and hair texture. Thirdly, "CRT suggests that dominant groups in society can manipulate and recreate racial groups in different ways at different times, to determine who is 'in' or 'out' of the dominant group" (Constance-Huggins, 2012, p. 7). Fourthly, "the interests of the oppressed are addressed only when they converge with the interests of the dominant group" (ConstanceHuggins, 2012, p. 8). The fifth aspect illustrates that historical accounts of racialized individuals are excluded from dominant groups' narratives (Constance-Huggins, 2012). These all suggest that there are systems in place, in society, that determine and continue the existence of the privileged and marginalized in society. As indicated, those systems of oppression are built on issues over which Black people often have no control. As a result, they are forced to change themselves in order to fit in, settle in the position of the 'out' group, or challenge the system. On the other hand, the dominant group is allowed to maintain their power.

CRT also addresses individual and systemic oppression (Constance-Huggins, 2012). This is a critical aspect, as the hope is to have changes at the individual and institutional level. "CRT suggests that the construction of race and the resulting institutional arrangements is one of these important mechanisms that shape the outcomes for racial minorities, thereby creating disparities" (Constance-Huggins, 2012, p. 10). While hair may be seen as separate from race, issues of hair are part of one's racial identity. Whiteness, beauty and power are intertwined together. According to Thobani (2007), "power governs human conduct, and while the state is a key aspect of this governance, force relations are pervasive throughout the social formation, permeating even the most civil, private, and intimate aspects of human life" (p. 24); we can see this play out in terms of how hair texture, straightness, length and styles are so often used to 
determine beauty, and forcefully or subtly dictate how Black females should wear their hair. On the other hand, CRT can be applied as it allows a way for the child protection workers to critically reflect on their practices, as a method to evaluate their position of authority over those under their care. Bringing this lens to child welfare work can encourage child protection workers not to control the behaviour of children in care or their parents but instead support the children with discretion, allowing private, personal decisions such as how to wear one's hair. For this research, it is important to have a strong understanding of race and hair from an institutional understanding, which is why CRT was the framework chosen.

Aylward (1999) focuses on the CRT framework from a legal standpoint. It is argued that CRT can be used to improve "the legal and social status of Black Canadians and other disadvantaged groups in society" (Aylward, 1999, p.134). The aim is to change present structural norms to have equality and social justice, as currently racialized individuals have limited power, as well as their voices need to be heard within child welfare agencies (Aylward, 1999). Furthermore, there are laws that affect the placement of Black children in care. Embedded in these laws is the history of racism which is perpetuated in the Canadian society and needs to be understood critically (Aylward, 1999). Slavery has also had major effects on how Black hair is considered in the beauty paradigm and it is important to raise consciousness within society by acknowledging the lived experiences of marginalized individuals such as Black children in the child welfare system (Aylward, 1999). Additionally, the intent of this paper is to empower Black individuals to define and celebrate their Blackness and Black hair. Recently, there have been attempts by different newspaper outlets to educate society on issues about Black youth in care, including issues related to their hair. Moreover, more Blacks are also utilizing social media to proudly display their Black hair styles - natural and processed - tell their stories about taking 
care of their hair, and embracing who they are, no longer allowing others to construct their identity or dictate what constitutes beautiful hair.

Narratives or storytelling are important aspect of CRT. CRT "attempts to expose the ordinariness of racism and to validate the narratives of people of colour, which are important bases for understanding laws that perpetuate their disenfranchisement" (Aylward, 1999, p. 35). Aylward (1999) further expressed that narrative allows social workers to share information of their clients in a non-historical way" (p. 85). This critical framework works in accordance with the narrative approach as during the interviews, protection workers were able to share their lived experiences of working with and understanding the grooming of Black youth in care, notably hair care.

"From the critical race theory point of view, rights of hair grooming choices are imprecise and therefore can be interpreted in ways that serve to reinforce existing social hierarchies" (Johnson, 2013, p. 4). Hence, the issue of dominance of one race over the other is reinforced in literature, the media, and as a societal norm projecting privileges upon those who have straight hair over those who have curly hair, not to mention kinky hair - thus perpetuating white beauty standards and dominance. On the contrary, the type of hair that one has should not determine one's value. Instead, it should be viewed as an array of artistic human differences, that make for a more interesting diverse and unique world. Ethnic differences are important to gain different perspectives and ideas and allows a society to advance. CRT is fitting for this topic as it addresses race, systemic issues and power. CRT "seeks to investigate the transforming process of the relationships among race, racism, and power through economics, history, context, feelings, group and self-interest, and unconscious interest” (Johnson, 2013, p. 4). 
The theoretical frameworks of the literature include feminist thought, Afro-Caribbean perspective, standpoint and Afro-centric theory. While these frameworks are important, they are limited in their critique of race and institutions. While there are differing views of feminist thought such as Black, Marxist or radical feminism, the primary focus is based on inequality based on the gender of female (Tong \& Botts, 2017). Afro-Caribbean perspectives focuses on the reframing of colonial history, while it provides a history of slavery and European dominance, it excludes Black individuals from other parts of the world (Henry, 2000). Standpoint theory “centres on how individuals' perspectives are shaped by experiences in social locations and groups" (Ellington, 2015, p. 23). Afro-centric theory "focuses on the research and practice of African peoples and peoples of the African Diaspora (Ellington, 2015, p. 24). While these theories individually offer interesting perspectives, CRT provides critical understanding of both racism and structures.

Having discussed how CRT will inform my work, I now turn to a discussion of organizational systems and cultural competency. I intentionally begin with cultural competency, given its obvious link to CRT. Cultural competency is defined as "a set of congruent behaviors, attitudes and policies that enables effective work in cross-cultural situations" (Pon, 2009, p. 60). However, the idea of cultural competency must be interrogated. Pon (2009) stated that cultural competency is an erasure of Canada's colonial history and racism, as it upholds dominant discourses. It is suggested for "social workers to gain awareness of how our own subjectivities influence how we construct and interact with others" (Pon, 2009, p. 65). The constant use of the word privilege, as opposed to marginalize and minority projects the established system of superiority over those with less or no value. In this way, we can see how straight hair constitutes the norm within dominant white culture, while curly and kinky hair defines the under privileged. 
While someone may assume they have become culturally competent in Black hair care, the very notion of doing so is in itself, an act of racism. "Social work's investment in cultural competency discourses may, in part, be symptomatic of social workers' desire to believe that Canada is largely a fair and tolerant society" (Pon, 2009, p. 66); in doing so, social workers also may avoid confronting and reflecting on Canada's history of whiteness and oppressiveness (Pon, 2009). While it may be important to understand the culture of clients, "this reifies culture in modernist ways, overlooking how culture is fluid, contested, hybrid, and not absolute" (Pon, 2009, p. 67). This will be an important conversation to further explore in the findings and discussion section.

Yee and Dumbrill (2003) discuss institutional issues and cultural competence that can deepen the CRT framework. "The recognition that an increasing number of people from diverse ethno-racial backgrounds are appearing on workers caseloads brings to the fore the urgent need to provide culturally relevant and appropriate services” (Yee \& Dumbrill, 2003, p. 98). James (1996) acknowledged that though social service organizations are a small part within the larger society, they continue to maintain the norms and values of society. Thus, it is not a surprise when we see the perpetuation of whiteness within organizations.

Through this research, it is the hope that there will be a better understanding of the culturally relevant and appropriate services within Ontario and in the child welfare agencies. Yee and Dumbrill (2003) acknowledged that it is difficult for social service agencies to provide culturally sensitive services to individuals from diverse populations. "Many within social work practice hold the view that if one can better understand the behaviour, culture, and perspectives of an ethno-racial group, then cultural respect, validation, and acceptance should follow" (Yee \& Dumbrill, 2003, p. 98). While it is believed that "a focus on race and ethnicity allows social work practitioners to hide behind cultural misunderstandings to explain why ethno-racial communities 
do not receive the services they need" (Yee \& Dumbrill, 2003, p. 100), it is my belief that not much emphasis has been placed on educating social work practitioners to understand and meet the diverse needs of Black youth in care, especially as it relates to the issue of hair and its relationship to culture and identity. It is a dilemma, how to understand and meet the hair care needs of Black youth in care, while also resisting the racist practice of pursuing cultural competency.

The training that social workers receive is embedded in white, European dominant views (James, 1996). "The essence of whiteness, therefore, lies in its power to establish and maintain a silent discourse that so equates normality with white culture that this culture becomes taken for granted as the norm" (Yee \& Dumbrill, 2003, p. 103). As a result of the power of agencies and the culture of whiteness, certain racialized communities have limited access to services and resources (Yee \& Dumbrill, 2003). Social service agencies have difficulties challenging the norm and structure of its system to have equitable services and supports for the Other (Yee \& Dumbrill, 2003). "If the ethno-racial 'Others' are not satisfied with the services they receive from mainstream agencies, the reason must be because 'they' are different, and those ethnoracial 'Others' should expect to receive culturally appropriate services only if, and when funding becomes available" (Yee \& Dumbrill, 2003, p. 108). In this way, we can see how some child protection services may view Black hair care training as a luxury to be afforded when funding permits.

James (1996) discussed "how insufficient attention to race, culture, and ethnicity hampers workers' ability to provide sensitive appropriate services...” (p. 140). The practices of workers, staff and boards' are governed by policies and are held responsible to higher structures in government (James, 1996). “Thus, remaining 'in business' does not depend on satisfying clients, 
but on satisfying budgetary and policy requirements established for specific services" (James, 1996, p. 144). Organizations based on mono-cultural models, "view racial and cultural diversity as an irrelevant factor in determining agency policies and practices" (James, 1996, p. 154). James (1996) suggested a multicultural approach model, which is meant to address and develop diverse programs that capture the need of racialized individuals to be involved (James, 1996). It is important that workers understand how culture plays in the lives of their clients (James, 1996). In addition, it would be paramount to have a diverse workforce of social work practitioners who are experienced in the norms of the youth's culture and with whom the youth can relate. Without these changes, organizations will continue to perpetuate whiteness, and that includes the ways in which child welfare services respond to hair care for Black youth in care.

CRT provides a framework that will guide the critique of the research, while including whiteness, cultural competency and organizational context as concepts to inform this work. As a result of racism which is embedded within varying structures in society, it is necessary to gain a better understanding on how Black hair relates to these guiding frameworks. 


\section{Chapter III: Literature Review}

While reviewing the literature that appeared pertinent to my area of research, I found some areas of interest. As a result, I have discussed below Black youth in care to provide an understanding to my subject area. I will then discuss areas that are relevant to Black hair care, providing a historical background and discussing the idea of dominant beauty. Once I provided an overview about Black hair, I then position this study in the context of child protection agency issues. I conclude the chapter by highlighting the limitations of current scholarly articles on this topic.

\section{Black Youth in Care}

Black youth are overrepresented within the child welfare system (Ashley \& Brown, 2015). Black youth represent $65 \%$ of the youth that are in care, according to the Ontario Association of Children's Aid Societies (Clarke, 2011, p. 275). Unfortunately, racialized children are usually within the foster care program long term (Daniel, 2011). In Nova Scotia, according to the Child and Family Services Act (1990), "when placing a child in a foster home, an agency shall ensure the child's best interests are served, taking into account the preservation of the child's cultural, racial and linguistic heritage, when practical” (Daniel, 2011, p. 2230).

"Similarly, in British Columbia, when deciding where to place a child, the director must consider the child's best interests according to Section 4 (1) of the Child, Family and Community Service Act (1996)" (Daniel, 2011, p. 2230). In Ontario, according to the Ontario Child Protection Standards (2016) "services to children and their families should be provided in a manner that respects cultural, religious and regional differences" (p. 13). In regard to the child's best interest, I will be focusing on Black children's cultural practices as it relates to hair grooming and the 
conception of beauty and identity. The focus here is, how are child protection workers assisting Black children and youth to preserve their cultural identity through their hair?

\section{Black Hair}

Historical background. The historical background on this subject is important to understand why hair is a significant identity marker. African hair is distinctive; it can be manipulated into many styles due to its unique texture (Johnson \& Bankhead, 2014). Also, African slaves wore hairstyles similar to their owners, which were popular at the time (Johnson \& Bankhead, 2014). This could be due to a variety of reasons such as their new surroundings, the hairstyling products that were made available, internalized oppression and whiteness. The African apartheid affected Black individuals as hair and the colour of one's skin were used to determine one's class, social and economic status (Johnson \& Bankhead, 2014; Oyedemi, 2016). In order to assess the texture of one's hair, a comb test was done. The texture of one's hair as well as one's complexion determined what class one would fit in (Oyedemi, 2016). Free slaves were placed in a higher class if they had lighter complexion and straighter hair, excluding Black individuals who were of a darker complexion and kinky hair, which also happened in America (Oyedemi, 2016, Robinson, 2011). While Oyedemi's article is focused on South African women, we can see how the information can be understood within a North American context. There were also forms of discrimination by some Black churches and organizations that utilized the brown paper bag test for skin tone and the fine-toothed comb or soda-can test for hair length and texture, which was used to refuse members (Brown, 2014). Also, Europeans would shave the heads of Africans when they entered America (Johnson \& Bankhead, 2014). A shaved head was considered the highest form of insult, as it erased the culture of slaves and characterized slaves as insignificant (Byrd \& Tharps, 2014). 
Throughout the years, there have been significant mixing of ethnicities creating a variety of skin tones and textures of Black hair ranging from coily to straight (Robinson, 2011). In some cultures, offering to braid another person's hair was considered a friendly gesture (Rosado, 2008, p. 60). It became a requirement for women to have "good hair" to enter certain spaces such as schools, churches and social groups (Rosado, 2008). Eventually, Sundays became a day off for African slaves in which slave women would gather and braid each other's hair (Ellis-Hervey et al., 2016). Many of the authors discussed the historical, cultural and social practices that have contributed to the current state of beauty and hair (Brown, 2014; Ellington, 2015; Johnson \& Bankhead, 2014; Oyedemi, 2016, Prince, 2009; Robinson, 2011; Rosado, 2003; Weitz, 2001). The majority of literature on the issue of hair is centered around women (Brooks \& McNair, 2015; Brown, 2014; Ellington, 2015; Johnson \& Bankhead, 2014; Oyedemi, 2016, Patton, 2006; Prince, 2009; Robinson, 2011; Rosado, 2003; Weitz, 2001). However, the same historical and societal norms influence Black males, including children and youth.

Dominant beauty. The media plays a large part in how beauty is perceived. The media promotes white beauty standards that exclude other races of women (Ellington, 2015). "Misrepresented, distorted or missing images send direct and indirect messages about what it means to be beautiful, and have beautiful hair and a beautiful body, as well as who has the power to define these beauty standards" (Johnson \& Bankhead, 2014, p. 89). Due to historic oppression and current media, many Black women prefer European and Asian textured hair as it is considered more beautiful (Oyedemi, 2016). Madame C.J Walker and Anna Turbo Malone designed hair care products that chemically straightened Black women's hair in the early 1900's (Johnson \& Bankhead, 2014). Straight hair was also achieved using a straightening comb which was made popular by Walker (Johnson \& Bankhead, 2014). "Instead of using a clothing iron or 
some of the other harmful methods utilized to accomplish the look of a straighter hair texture, African American women were able to more easily achieve a style that they feel would afford them greater social and economic mobility" (Johnson \& Bankhead, 2014, p. 88). This notion of social and economic mobility is connected to whiteness, where these Black women felt they needed white hairstyles to be successful in society. However, many Black women also felt that replicating these styles are based on white standards of beauty that denied their own beauty (Johnson \& Bankhead, 2014). Since birth, it seems Black people have been taught that their hair is problematic and as a result there remains a lack of knowledge about maintaining their natural hair (Ellington, 2015; Johnson \& Bankhead, 2014). According to Prince (2009), "the hair on a Black woman's head is treated as it is a separate entity from the rest of her body...” (p. 14).

“The concept of 'getting' one's hair 'done' holds paramount value with African communities in the United States and globally" (Johnson \& Bankhead, 2014, p. 88). Because of this concept, I would like to understand if this is enacted with Black children in care. Black women tend to spend more money on hair care products than other racialized women (Johnson \& Bankhead, 2014). In addition, Black women would spend about 50 hours a month on having a weave installed, while natural haired Black women spent about twenty hours on styling and maintaining their hair (Rosado, 2008). Hair care has an effect on women's finances. Rosado (2008) notes that women spent about $\$ 200$ per year on weaves and/or $\$ 800$ per year on perms, while women with natural hair spent about $\$ 300$ per year. Are children in care provided with enough money for hair care maintenance and services appropriate to Black hair care practices?

The notion of 'good' or 'bad' hair. 'Good hair' is described as hair on individuals with European, Asian and Indigenous ancestry, who have long, wavy or straight hair, while 'bad hair' is considered African textured hair such as being thick, coiled and short (Robinson, 2011). 
Ellington (2015) acknowledged that the participants in her study viewed good hair as healthy hair. This is a new perspective that I have viewed within the literature. The idea of good hair as healthy hair is positive and can change how individuals view their hair. It seems an approach that both ignores and resists the whiteness of beauty standards is paramount, as all forms of hair can be healthy.

Women's natural hair can be styled in many ways such as with dreadlocks, braiding, and afro, as well as the use of extensions or wearing of wigs (Ellis-Hervey et al., 2016). In the hair world, there is a hair typing system which to some seems hierarchal. The hair system has four types, where type 4 hair is considered kinky, type 3 hair is curly, wavy hair is type 2 and type 1 is straight hair (Ellis-Hervey et al., 2016). Type 1 hair is considered the norm and dominant standard of beauty (Ellis-Hervey et al., 2016). From an early age, Black children's hair is altered through braiding and twisting by their guardians (Ellis-Hervey et al., 2016). Black females learn about negative and positive messages about their hair from parents, other adults, peers, and men (Robinson, 2011). "Hair alteration is not necessarily a result of self-hatred, nor a desire to be white, but about working within internalized beauty paradigms to attain one small piece of what society defines as beautiful" (Ellis-Hervey et al., 2016, p. 874). However, it is important to note that natural hair takes more effort and care than straightened hair (Ellis-Hervey et al., 2016). Although naturally textured hair is considered 'bad' hair, it is very versatile (Robinson, 2011). Given the effort and care needed, I wonder how well Black children's hair is maintained in child protection services, especially consider how large the workers' caseloads are.

Oyedemi (2016) states that "the process of attaining 'beautiful' hair is enmeshed with all forms of violence: physical, direct, structural, cultural and symbolic" (p. 538). In the documentary by Chris Rock called Good Hair (2009), the show "illustrates, the connection of 
hair to beauty intersect with race and gender, placing a particular burden on Black females whose naturally kinky hair textures are low on beauty continuums" (Robinson, 2011, p. 358). These are just two examples of important sources of information about how Black hair is connected to issues of sexism and racism. Whether about hair or other aspects of Black identity, there are many African Americans authors that have tailored their books for children to confront white norms and racism (Brooks \& McNair, 2015). Though African literature is circulated within society, I wonder how many children have had access to reading these books, and if they have, how that has influenced their attitude about their hair?

Resistance. It is problematic that Thompson (2009) shared "it has been the intent of this article to refute the notion that Black women are liberated from their hair" (p. 854), which shows that the article is one-sided and generalizes all Black women. It is important to note that not everyone maintains specific norms of beauty (Weitz, 2001). Weitz (2001) highlighted that the racialized body is constantly fighting for power. Resistance can be through small acts such as making fun of individuals in power, or performing femininity in cunning ways (Weitz, 2001). Weitz (2001) suggested that individuals can resist power through traditional strategies, by refuting mainstream ideas about attractiveness, but highlighted that one cannot control who will respond and how. As a hair style goes out of fashion, "those who continue to wear it look merely dated and unfashionable, as their hairstyles lose their political meaning" (Weitz, 2001, p. 683). Hence, hairstyle should not be motivated by fashion, but choice. Weitz (2001) generalizes and focused on all women; however, there are women who sport their natural hair with pride. It would be helpful if Weitz utilized samples of participants with natural hair. Weitz (2001) mentioned non-traditional ways of resisting, such as intentionally not wearing your hair in a 'normal' feminine manner (Weitz, 2001). This suggests that if one wears their hair naturally, 
they are not feminine. Yet we can see resistance as an important part of decision-making and autonomy for women regarding their hair. For children, how much are they a part of the decision-making process regarding the styles of their hair?

The politicization or symbolic meaning of hair for Black women is lost when white dominant groups promote it as commodity or wear hairstyles for pleasure. This issue was not addressed in any of the literature that was found. "While individually not all African American women valorize white beauty standards, African American women have had to invent their own beauty measures" (Patton, 2006, p. 27). However, Black children within a white dominated institution may have little resistance or be saddled with the norms of the beauty world due to a lack of resources and choice, especially given that the age of Black children and youth can limit the decisions they are able to make while in care. Having discussed the factors relevant to my discussion of Black hair, I now move on to how this relates to issues in child protection agencies.

\section{Agency Issues}

Much of the literature is based on African American youth; however, there are similarities on how Black youth are affected culturally by being in child welfare systems in Canada. "This trend is likely to continue due to three factors: (1) the disparate treatment of ethnic minority families in the foster care system, (2) the racial composition of potential adoptive parents, and (3) the specific preferences of these parents" (Padilla et al., 2010, p. 51). Daniel (2011) explained that "transcultural foster placement occurs when children and youth from racialized groups are placed with foster parents from a different racial or cultural background than children" (p. 2231). Due to the increase of Black children in care, there are limited foster parents that fit a particular background and race which results in children being placed in random foster homes that cannot appropriately support the needs of the children (Daniel, 2011). 
"Although foster parents are required to participate in training, it has been documented that only a few foster parents actually receive post licensure training on working with teens, children who had been sexually abused, children with disabilities, and children of a different race than that of the foster parents" (Daniel, 2011, p. 2231). The lack of training is due to "factors such as lack of resources, scheduling problems, transportation issues, access to respite care in order to attend training, and a lack of priority given to training by the foster care system" (Daniel, 2011, p. 2231). Despite these challenges, there should be on-going training; but which voices are being included or excluded, and from which source or perspective is the information being taught? There should be productive collaboration between the workers in the foster care system, the biological parents, and the children in care who can make some decisions or offer suggestions about their own hair care. This would serve to bridge the racial gap that is often used by the white dominant groups, to control and dictate how Black children should groom their hair. Team work could educate and inform all the factors involved in working together, to ensure the best interest of Black individuals, in developing positive self-images that are not determined by their hair.

Cross cultural training especially where the workers are predominantly white but serve a Black population in child welfare, could create awareness, sensitivity, and allow workers to attend to the whole child. These workers could learn how to focus on developing positive characteristics and a strong self-image in children and the youth, so that hair and its overwhelming relationship to physical beauty will soon become a white myth. The aspiration is that the child welfare system will become the institution that takes on the initiative to revise the dictates that control Black beauty, and resisting the restrictions to beauty being defined by specific white physical attributes. Instead, they should focus on developing beautiful traits and a 
strong thinking, decisive mind in young Black children. However, as noted in the theoretical framework, cross-cultural training, as a form of cultural competency, can be problematic.

According to Ashley and Brown (2015), many youths are irritated by the condition of their hair and are unaware of how to handle it. Therefore, they choose to use straightening chemicals or add hair extensions, which allow them to manage their own hair care. When children's hair is being combed it provides "the opportunity for close contact and physical touch" (Ashley \& Brown, 2015, p. 592). This will "offer an opportunity for internalized parental acceptance, racial identity, and improved self-esteem" (Ashley \& Brown, 2015, p. 592). Ashley and Brown (2015) shared that in further interviews, their research participants indicated that many Black women are interested in their hair. "However, participants noted that embracing their own hair would be impossible without support and guidance" (Ashley \& Brown, 2015, p. 598). "For African American foster youth, especially females, hair care may be an invaluable vehicle to support healthy racial identity development and improved relationships, elements absent from traditional treatment models" (Ashley \& Brown, 2015, p. 599).

Foster parents should be provided with cultural resources by child protection agencies (Daniel, 2011). According to many foster parents, they had to research and find their own resources and activities on cultural practices (Daniel, 2011). Daniel (2015) recognized "that foster parents made decisions related to the cultural development of children in isolation, with little or no input from child protection agency workers" (Daniel, 2011, p. 2237). As a result, foster parents were made accountable for forming relationships with children and youth, with cultural people within the community (Daniel, 2011). I agree that "future research is required to develop a consultative and collaborative process for working with child protection agencies, biological families, children and youth from racialized groups, foster parents as well as 
communities" (Daniel, 2011, p. 2239). Moreover, it is problematic if foster parents are learning information through incorrect sources in the community. Child welfare workers and agencies are to ensure that transracial children's cultural practices, identity and ethnicity are infused into their daily lives (Padilla et al., 2010). According to Padilla et al. (2010), "parents with cultural training are perceived as more warm and compassionate by their transracially adopted children, facilitating a greater sense of belongingness to the family" (p. 67). While this may be true for some, there are still many children who may not share these feelings.

"Despite efforts to increase ethnic minority representation, prospective adoptive parents continue to be primarily well-educated, affluent" (Padilla et al., 2010, p. 53). Structural barriers such as cultural differences, racial discrimination, and failure to seek potential Black individuals to adopt have limited the number of racialized people that could possibly be adoptive parents in the child welfare system (McRoy \& Griffen, 2012; Padilla et al., 2010). However, I am cautious in saying that having racialized foster parents will have a better effect on Black youth hair care practices or other cultural practices. "Caregivers may opt not to participate in services or may face barriers to accessing services which are outside the control of caseworkers or agencies" (Font, 2013, p. 374). Font (2013) shared that "no known studies examine the role of caseworker race or the interaction between child race and worker race in service referral decisions" (p. 374). Due to the limited literature on this topic it is suggested by researchers that the race of a caseworker affects how a family is assessed (Font, 2013). "Yet, the unavailability of services in different regions may contribute to disparities, with families from under-resourced areas receiving fewer or less relevant services" (Font, 2013, p. 384). Font (2013) acknowledged that “additional research, using more exploratory approaches such as direct interviews with caseworkers and agencies, may be useful to help determine how caseworkers make service 
referral decisions, and how government and agency policies guide workers in their decisionmaking" (p. 387). Furthermore, child welfare services that have contracts with outside service provider tend to have long waiting list and minimal services, especially in rural and marginalized areas (Font, 2013). These factors could further hinder culturally appropriate approaches to hair care for Black children and youth in child protection care. I would like to explore the referrals and supports caseworkers use within the community with respect to these needs.

The lack of research in these areas has been noted by many authors. Robinson (2011) believed that there is a lack of research on the experiences of young children who are impacted by colourism. Ellis-Hervey et al. (2016) note that

If educators were to have a greater knowledge base of specific struggles associated with not fitting in with the typical standards of beauty, they would position themselves to provide more transparent and empathetic educational and psychological interventions and supports, reducing instances of negative self-perception (p. 880).

Marshall and Haight (2014) add "professionals in this study described difficulties arising from high caseloads coupled with the need to make complex decisions in stressful and potentially dangerous situations" (p. 89). They continue, noting that in their study, A European American child welfare professional provided an example of how, under the scrutiny of child welfare professionals, the significance of some parenting behaviors is magnified (e.g., eye contact) while others go unnoticed (e.g., braiding hair), leading to culturally biased assessments of parenting (Marshall \& Haight, 2014, p. 86).

The various literature from North America and Europe show similarities in issues that happen as a result of Black youth in care. Foster parents and agencies need to learn cultural practices of Black children in care so that they can build positive lasting relationships. By 
learning and identifying the various options in caring for Black hair, some of the stigma that are attached to having Black hair could be reduced. This in turn could lessen or remove some of the oppressions that Black individuals experience. The literature focused on issues that foster parents encounter, but is limited on the child protection worker's perspective.

\section{Gaps in the Research}

Although many authors have done important research, there are many gaps within the articles. Many of the research studies asked similar questions about hair, though different populations were used. The research lacks examining the impact of colourism on young children and youth, who have limited recordings of their lived experiences, especially children within the child welfare system (Robinson, 2016). There is a lack of academic studies surrounding Black female issues regarding the child welfare system, where within a structure, Black individual voices are constantly disregarded. Canadian scholarly articles on issues of Black individuals and their hair are limited, especially regarding the child welfare system. Robinson (2011) stated that race is usually studied based on Black males, particularly around Black masculinity and negative stereotypes. This provides me with a reason to focus on all Black individuals within the child welfare system.

Greene (2011) suggested that future research should be done on the lack of Black women's civil rights. In this research, it would be interesting to understand Black children's resistive practices that can be utilized within the child welfare institution. Also, it is important to learn how the child welfare system implements policies that continue to disenfranchise youth and their access to cultural services. Due to the lack of research and gaps in information on literature reviewed, I would like to explore further, child protection worker's experiences in providing hair care services for Black youth in care. 


\section{Chapter IV: Methodology}

This chapter will elaborate on the research design process. The sampling, recruitment strategy, data collection and analysis plans will be explored. Given the vast number of Black youth in care, I am interested in understanding and learning more about the training or conversations about hair care that child protection workers encounter with their clients. Furthermore, I wish to learn where agencies are receiving cultural-based information. To explore these issues, I have used a qualitative research method. Qualitative research focuses on understanding the meanings that individuals assign to societal issues (Creswell \& Poth, 2017). I explored the research through narrative research which is used to study the lives of individuals in which they share their stories (Creswell \& Poth, 2017). Much of the research that I found and discussed in the literature review used a qualitative research method, while a few used quantitative or mixed methods. Quantitative research that utilized closed ended questionnaires limits the participant from explaining their point. Hence, the need for a narrative approach.

The narrative approach provided a way for the participants to share their stories in a comfortable way, as "storytelling is a natural way of recounting experience" (Moen, 2006, p. 56). Through narrative stories participants shared their experiences, and "they may shed light on the identities of individuals and how they see themselves" (Creswell \& Poth, 2013, p. 71). A narrative approach allowed participants to feel equal to the researcher as they are the expert of their story (Moen, 2006). "Within this approach, the research subject is regarded as a collaborator rather than an informant guided by the agenda of the researcher" (Moen, 2006, p. 61). "Narrative methods may be relevant when trying to understand social workers' interaction processes with their clients and their talk about those clients with other professionals" (Larsson \& Sjoblom, 2010, p. 273). "Narrative accounts give us access to the identity constructions of 
individuals and can be a good strategy for giving voice to minority and/or discriminated groups" (Larsson \& Sjoblom, 2010, p. 274). While my study is not with 'minority groups', it is about the experiences of providing services to Black children and youth.

It would be relevant to hear different stories, allowing workers to shed light on the practices and trainings within their agency as Moen (2016) suggested "we create narrative descriptions about our experiences for ourselves and others, and we also develop narratives to make sense of the behavior of others" (Moen, 2006, p. 56). The use of narrative research allows for a conversation to continue around the culture of Black hair in the child welfare system. Since the purpose of this study is to understand the experiences of child protection workers dealing with Black children hair, narratives can allow participants to establish their stories about this topic.

The sampling used was purposive, as the participants represented a certain criterion, such as being a social worker or child protection worker working within a child welfare agency. I intended to sample three to five social workers, within the Children's Aid Societies in Ontario. There was no specific race or ethnicity categories, as each worker, no matter race or ethnicity, can offer a story of their experience. Child protection workers were interviewed face to face, wherever they were comfortable to meet. The narratives were "collective stories that are shaped by the addresses and the cultural, historical and institutional settings in which they occur" (Moen, 2006, p. 61). Social workers were encouraged to participate if they were 18 years of age or older, and have worked with and provided care for Black children, as frontline workers who work closely with their clients on a regular basis.

Social workers are provided an opportunity to voice the challenges that arise in their practices. This allows the institution to look at their current practices and suggest possible 
alternatives. Though all departments work in some way with their clients, departments such as foster care and kinships can provide an interesting perspective as majority of racialized children are placed in non-ethnic foster placements.

Because of the shortage of foster parents nationwide, placements are often made based on the availability of foster parents rather than on an appropriate fit between the background, experience and skills of foster parents and the needs of the children (Daniel, 2011, p. 2231).

There are no other research criteria for participants.

Participants were recruited through email and flyers within one Children's Aid Society within south-central Ontario. The interviews were semi-structured and were 10 to 20 minutes long in a single session. Open-ended questioning allows for an open dialogue and follow up on the questions asked (Turner, 2010). In order to have a conversation between the interviewer and the participant, open-ended questions are essential (Maykut \& Morehouse, 1994). There were nine questions asked in the interview. Some of those nine questions are: What happens to a Black female child who comes into care and is not able to care for her own hair? What hair care resources are in place? What determines where a Black child is placed? Who is responsible for providing hair care for Black youth? A consent form was provided to participants through email prior to meeting for the interview. The consent form states that participation is completely voluntary and if participants choose not to participate it will not impact their relationship with the researcher, Ryerson University and the Children's Aid Societies.

The participants included three female child protection workers who are currently working in the field. The participants have varying years of experience and all work in different departments within the organization. It was important that workers from particular departments 
such as Children's Services, Placement and Young Parent team were chosen, as they work closely with children for a period of time. As well, in these roles they are interacting with biological parents or caregivers and foster parents. The reason for the variety in departments, is that social workers in different areas can offer different perspectives.

I am completing my placement at a Children's Aid Society, which provided me with contact to a supervisor who was able to email fellow colleagues for recruitments. I was given permission to email my flyer to the appropriate supervisors to share with their staff. Once interest was established to participate, a time and meeting place was discussed. The consent form was emailed to the worker once interest was stated. The consent forms were signed and reviewed before the interview began. The interview lasted between 10-20 minutes. The consent forms stated that participants have two weeks to withdraw after the interview, however after the data analysis has begun they can no longer withdraw. Confidentiality was maintained through masking the participants name and place of work, as pseudonyms were assigned. However, participants were informed that if concerns were disclosed during the interview in respect to a child's safety, there is a duty to report. Participants were entitled to two bus tokens or a $\$ 10$ gas card as reimbursement. One participant opted out of accepting the $\$ 10$ gas card. Participants were audio recorded which was stated on the consent form. The recordings were password protected, then downloaded, transcribed verbatim then deleted immediately. Data were secured and stored safely in a locked cabinet and transcriptions were password protected.

For me, there were moments of nervousness, going into a white organization and asking how they were servicing the children and youth in their care who have the same colour as myself. It was important to remain neutral in response to the answers that were given in the 
interviews. I did not want to be judgmental or concerned due to issues that were coming up during the interviews.

The analysis of the research was coded through themes that appeared from the data (Creswell \& Poth, 2017). When there were too many themes, through further analysis they were explored and categorized with other themes into broader themes. Coding "is a discrete analysis step where the observed meaning in the text is systematically sorted into categories, types, and relationships of meaning" (Guest et al., 2012, p. 52). The data was collected and analyzed, and the following chapters will discuss the interpretation of the findings. As a result of confidentiality, the names of the workers are changed. The research brought to light the limited hair resources that child protection workers have regarding caring for Black children in care. This may contribute to current knowledge about the issues facing Black children and youth in care. There are no anticipated direct potential benefits to participants. However, the information shared will help in implementing appropriate hair care services for the children. 


\section{Chapter V: Findings}

This chapter will present the findings from the interviews of three child protection workers in Ontario. They explained their roles and experiences working with Black children and youth who are in care. The major themes include whiteness of foster care, communication between CAS and Parents, resources and knowledge about hair care. These themes emerged through a thematic analysis which also included the responsibility of the family and the workers involved, resources and training or lack thereof. The workers are aware of racial differences between a child and the foster parents. Furthermore, the workers understood that there are limited foster placements available. While all child protection workers interviewed are from the same agency, each came from different departments and had varying child welfare experience. Highlighted below are responses from participants. As a result of maintaining confidentiality, names are not used and participants are labelled as a number.

\section{Whiteness of Foster Care}

The participants interviewed acknowledged the whiteness of the foster parents within this particular city, noting that they also are aware that this creates challenges regarding the placement of racialized children and youth. Participant 2 indicates that there are limited racialized foster parents within the system.

The majority of our foster parents are from Christian Caucasian homes and so if that's what's available then you know that's where children go

Participant 1 explained that currently there are seven cases of Black or biracial children that were on the participant's caseload. Child protection workers have a responsibility to communicate with the family of the child who is a part of the welfare system to provide the 
foster parents with accurate cultural practices. Also, discusses the limited placements available to children. Participant 1 adds

Typically, we always try to have kids in homes that they can culturally identify to;

however, sometimes we don't have a lot of placements available to us. So, in the event that we don't have a placement available to us then children are placed in a home that will best meet their needs, but they may not culturally identify. However, if there is any cultural needs or practices then we usually gather that information from the parents and then inform the foster parents who then try to continue with those practices in the home.

\section{Communication between CAS and Parents}

Though children are taken out of the care of their parents or guardians, parents still have some forms of power in how their children's hair is cared for while in care. Once children are within the society's care, parents have limited access to their children. However, parents still have control and input over how their children daily needs are met, highlighting the importance of communication between caregivers, child protection workers and the foster parents.

Communication is vital in regard to a child's hair care.

P2: If a child comes into care under a temporary care agreement then part of what we need to do is to consult with the parents if we're making any sort of changes to their hair, so I guess if a parent were not happy with what their child wanted there would need to be a discussion between the parent and the child. ${ }^{1}$

Child protection workers play a significant role, in that they are the middle person who coordinates all parties who are involved with a child. Once a child is in the care of the Society,

\footnotetext{
${ }^{1}$ A temporary care agreement, according to the Child and Family Services Act (1990) under section 29(1), describes that "a person who is temporarily unable to care adequately for a child in his or her custody, and the society jurisdiction where the person resides, may make a written agreement for the society's care and custody of the child".
} 
workers have to communicate with the family, school staff, health care professionals and other social workers. Through my discussion with the workers, workers recognize that they have limited understanding of the cultural practices of Black hair and thus often seek guidance and support from family members.

P3: I would contact the family in regard to the care of their child's care as I know little about the care of Black children's hair.

P2: we are not allowed to cut or change children's hair without permission from their parents.

Parents have a role to play in their children's development, when the children were in their parents' primary care, they likely had a particular regime for the child's hair.

P2: Usually we do encourage foster parents and parents to communicate at the very least through the communication book that goes back and forth and I know that there have been times when we have specifically had it that the parents would do the children's hair while they're visiting to make sure that it's being cared for the way they want it and because they are more adept and comfortable with it.

It was illustrated that workers try to abide by the same practices as the parents when providing hair care for the children. Child protection workers have the difficulty of advocating for the child they are caring for, while abiding by parents' wants and needs.

P2: so while you would think that as children get older they should have more say about that I'm certain not with teenagers they do but a lot of time even when children are saying I really want my hair cut if mommy says no then we cannot do that 


\section{Resources}

Another theme that evolved dealt with resources, whether in the community or with individual members. For resources related to hair care to be possible, funding is needed to access hair products. This indicates the importance of economics within the child welfare system. One participant reflected back on a previous role they had and recalled

P3: When I worked in a group home setting, the youth was the best resource for locating resources for their hair care needs. Funds and transportation were provided and the youth were provided with the products and essentials that were required in order to properly care for their hair.

Also foster parents, family members and friends are also used as resources.

P1: if some of [the foster parents] have their own personal experiences which works out nicely, so I had a home where the foster mom's daughter had was in a biracial relationship and so she knew a lot of the cultural dishes through her daughter and those foster kids would spend time with her grandkids who they were able to identify with them so it worked out nicely that way.

In a time where information is easily accessible, there is a wider range of hair care products and resources. As such, it is not uncommon for the workers to seek community assistance.

P1: we look at salons also go a lot off of what parents have been using and then we research it online we order it off line, so I know in one case that I have the foster mom was actually a hairdresser so she had consulted with her coworkers on how to manage one of my youth's hair and so that's how she was being maintaining it in her home. A pamphlet on hair care was given to the researcher. The participant explained that the pamphlet was created by a Black worker that previously worked at the agency. The pamphlet is 
given to foster parents, when needed. The pamphlet provides an overview of the resources within the city, such as drug stores and salons from which to buy products to do a Black child's hair.

P2: my role is to be a placement worker in the foster homes so there's certainly been Black children in some of the foster homes that I am responsible for and so I haven't dealt with the children's hair personally, we have a handout that we provide to all foster parents that talks a little bit about caring for children hair and skin for black children so we provide that regularly and I try and connect them with other foster parents who have cared for children with that hair as well if it's something they are not knowledgeable about or aren't comfortable with and there is a list on there I believe of products to purchase and possible salons that they can frequent

While the pamphlet discussed above is very helpful to workers and foster parents, it is important to note that workers are only aware of resources within the community because of the pamphlet written by a past worker, with P2 noting knowledge of these resources is : "only from that pamphlet". This raises questions about what the Children's Aid Society is doing on an institutional level to provide information to workers and foster parents about both the practices and products related to Black hair care.

P2: we tell people that most Walmarts and most drug stores you can get these products and you can ask employees there who might have some knowledge but we don't really have anything here that we give out to anyone and again we encourage them to ask parents like what do you usually use if the parents are open to those conversations. Workers have had to advocate for children to get specific hairstyles. It was highlighted that children are responsible for saving their allowances to purchase products for their hair care needs, as the Society is not able to provide them with enough funds. 
P1: I have 1 young lady who has been using do-gro in her hair to keep it moisturized and to help with um what she calls frizz control so we do make exceptions and have special purchases made for her to get hair products that she needs in addition to special shampoos and conditioners to help with that.

P1 further noted,

P1: depending, like sometimes we've had girls who've wanted to get extensions or get their hair like get braids things that were costing like quite a bit of money so we put that we requested through special funding or they put a portion of their allowance towards maintaining it because I know the up keep can be expensive but we do always ask or a lot of our youth are open to asking us if they are needing something done with their hair. The Society has a responsibility to support and provide for the hair care needs of the children and youth in their care.

P1: The Society would be part of if like they are in our care, its part of their cultural heritage to be able to support that.

Residential homes or outside paid resources are responsible for the care of the children that are placed in their care.

P1: so if they were in a group home or an outside paid resource they would then be responsible for purchasing those products.

Also, children are provided with funds that assist with basic needs as noted above.

\section{Knowledge About Hair Care}

Workers have had to learn of a child hair care needs from previous experience through personal work with the children. 
P3: Unfortunately, from previous experiences, I discovered that learning how to care for a Black child's hair isn't the same as caring for a white child's hair. Being a staff member in a group home with very strict rules and policies, while being unaware of the cultural differences that exist between myself and other cultures, it is important to have the cultural competence and understand the diverse needs of different cultural groups than our own. Assuming that caring for a Black child's hair is similar to caring for my own hair is an assumption that was incorrect and turned out damaging the youth's hair.

The same participant noted further that

P3: Using products that are made for her hair type was something I had not previously considered before that incident had occurred. Now, I am more aware of how to find resources and products for Black youth who are unable or unwilling to care for their own hair.

The child protection workers were asked if residential home workers were provided with training on how to care for Black children's hair.

P3: "No. Not that I am aware of. I worked in a group home facility for over five years and did not receive any training on how to take care of Black children and youth's hair". P1: I'm not a 100 percent sure that anyone has had training on it, no I don't, I don't know.

\section{Conclusion}

The participants shared their experiences working within the field and shared similar themes. These themes include whiteness in foster care, communication between CAS and parents, resources, and knowledge about hair. The findings offer an internal understanding of the 
issues that are happening within child welfare. The themes have been supported by literature which will be further explored in the discussion section. 


\section{Chapter VI: Discussion}

Hair, which is considered the crown of a Black individuals head, has many implications within the child welfare system. There are interesting issues that arose from the findings. The main theme that is shown deals with responsibility, who is responsible to provide care in regard to hair care? The role and decision making that each person plays in a child's life with regard to a child's hair is important. The child welfare system is meant to protect a child and as a result have responsibilities for children in the state's care. The culture of a child continues though they may not be in the care of their biological parents or caregivers. The Ontario Child Protection Standards (2016) acknowledges that "it is important for child welfare professionals to have an overall awareness of the diverse background of the families served in each community and in particular, to engage families in dialogue about their backgrounds" (p. 14).

\section{Whiteness and Power}

It is important to note that all the workers that were interviewed were white women.

"Certainly, child welfare workers, which in countless studies have been reported to be predominantly white, are increasingly working with a greater number of children and families of African American or Latino descent" (Everett, 2004, p. 89). Child welfare is based on Eurocentric norms and whiteness, hence due to the growing number of Black youth in care, culturally relevant training services are needed. As Healy (2005) states, "the social work role is intensely a political role in which social workers occupy a privileged status, at least in contrast with service users" (p. 180). It is important that child protection workers reflect on how one's social location can shape their practice with other individuals (Healy, 2005).

Whiteness in Canada and the mechanism through which white oppression masks its race and power is to deconstruct what is normally not named and, more significantly, to 
challenge processes that perpetuate the status quo for failing to provide culturally appropriate services (Yee \& Dumbrill, 2003, p. 101).

It would be interesting to discuss this with a male or a person of colour, as this will provide an unique perspective. A Black worker may have an interesting perspective, if they have faced an oppressive work environment due to their hair. However, being in a privileged position such as being a child protection worker comes with a lot of power, in addition to being white. Child protection workers can make decisions that can affect one's life. Yet, they are also women who are seen as caring and may understand a lot more about hair than possibly their male counterparts.

Once a child is placed in foster care, the power is shifted to the foster care placement from the social worker due to a contractual agreement that is put in place (Daniel, 2011). This continues a cycle of white power, as most foster parents are predominately white. Thoburn, Chand and Procter (2005) agree "that most of those in long-stay arrangements are black African children placed with white foster parents" (p. 124). Subsequently, based on this agreement foster parents are given power to meet the needs of the child or children placed in their care (Daniel, 2011). Moreover, foster parents are positioned to determine the cultural needs of the child by abiding to a contractual agreement (Daniel, 2011).

A shortage of foster parents of diverse cultures, coupled with an overrepresentation of children of minority cultures in the child welfare system, has resulted in a dire need for transcultural placements - that is, placing children in families that do not share their cultures, meaning a common history, tradition, values, and social organization (Coakley \& Buehler, 2008, p. 402). 
"When a child from a racialized group leaves their birth family and moves in with a Caucasian family, there will be cultural differences that both parties need help understanding, no matter how loving the foster family" (Daniel, 2011, p. 2231).

\section{Hair and Attachment}

Even though children are out of their parent's care, parents are still somewhat involved, in their children's lives. According to the Child and Family Services Act, service providers shall ensure that children and their parents have an opportunity, where appropriate to be heard and represented when decisions affecting their interests are made and to be heard when they have concerns about the services they are receiving (R.S.O. 1990, c. C. 11, s. 2).

The findings suggest that parents still have power in how their child's hair is cared for. They have a right on the style and cut of a child's hair. Though the child welfare structure is oppressive, parents still have some power in how their children's basic needs are maintained. However, parents need to educate themselves on their rights and responsibilities when their children are in foster care.

Parents can continue to maintain an attachment to their child through hair care, such as hair combing. One of the child protection workers mentioned that parents are encouraged to do their child's hair at access visits. While there is power to have parents comb their child's hair, there is "power with" as parents and worker can work together to achieve an agreed goal (Dumbrill, 2003, p. 113). "Parent visitation, the scheduled face-to-face contact between parents and their children in foster care, is considered the primary child welfare intervention for maintaining parent-child relationships necessary for successful family reunification" (Haight et al., 2001, p. 1). 
Nesmith et al. (2017) shared that it is encouraged that foster parents build a relationship with the biological parents or caregivers. "They believed that respect, communication and a strong working alliance benefitted the children as well as the parents" (Nesmith et al., 2017, p. 252). One participant highlighted that a communication book is used for parents and foster parents to communicate. This book allows for both sets of parents to be up-to-date with how the children are doing. Entries in this book can include matters related to hair care. This is important given that parents have to give permission for changes in a child's hair style.

"During hair combing, mothers must repeatedly touch, pat, and smooth a child's hair" (Lewis, 1999, p. 506). In addition, the child is able to sit on their mother's lap or between her legs, creating attachment through skin contact (Lewis, 1999). Hair combing requires touch through massaging the child's scalp with various products such as oils or creams (Lewis, 1999). However, this activity creates contact and bonding relationship. According to Lewis (1999) "the functional aspects of hair combing offer an opportunity for attachment, as well as intense emotional intimacy between mother and child" (p. 506). The fact that child protection workers can initiate this simple technique with the parents, allows the child to have some normalcy. A participant mentioned that parents are encouraged to do their child's hair during visits; however, perhaps this is not based on maintaining attachment as much as to the difficulties foster parents experience with Black hair care.

There are many hairstyles that a child can have from braids, twist, curls, cornrows and extensions (Lewis, 1999). However, these styles require differing amounts of time to do which can take up to a minute or a number of hours (Lewis, 1999). In addition, depending on the style of choice, they can last for different amounts of time (Lewis, 1999). "Thus, parent and child spend a substantial amount of time on a one-to-one basis" (Lewis, 1999, p. 511). In a child 
welfare setting where there are supervised visits, attachment through hair combing could be observed. Although, there could be cultural biases from the worker who is observing. As well for particular hairstyles, there may not be enough time during the visits to complete the chosen style. "Within African American families, racial characteristics such as hair texture are often tied to affective qualities in attachment relationships" (Ashley \& Brown, 2015, p. 591). When a primary guardian combs a child's hair, this interaction provides intimacy and physical touch for children (Ashley \& Brown, 2015). "Hair care retains a powerful role in attachment relationships for Black youth, and may provide both a context and a vehicle for attachment and nurturing" (Ashley \& Brown, 2015, p. 592). "Hair combing interactions signify the critical role of skin-to-skin interaction, nurturing, and emotional intimacy between caregiver and child; furthermore, they offer an opportunity for internalized parental acceptance, racial identity, and improved self-esteem" (Ashley \& Brown, 2015, p. 592). This awareness can provide professionals with an understanding on how to maintain culturally relevant issues in children's lives (Ashley \& Brown, 2015). Prince (2009) recognises that "hair is at the heart of many Black women's sense of who they are in the wider world that they navigate daily" (p. 16).

The child protection workers acknowledged the importance of communication and consulting with the caregivers. While being in care may not be the ideal situation, parents continue to be present in their child's life whenever possible. Also, parents providing consultation can help to avoid disastrous hair care practices and maintain the healthy norms in the home. "Hair care interactions may address innumerable parenting needs by providing a context for healthy touch, nurturing, emotional intimacy, and fostering the potential for attachment" (Ashley \& Brown, 2015, p. 599). Healthy attachment and bonding can be something that continues to be encouraged in child welfare. It is important that parent-child relationships 
are maintained through healthy attachment, through simple interactions and communication during hair care. Hence, the need to provide appropriate training to service providers.

\section{Managing Hair}

Hair is a physical characteristic that constructs and characterizes people into racial categories (Constance-Huggins, 2012). The worker mentioned that foster parents found Black hair difficult to manage. This idea is perplexing and continues to maintain a negative discourse about hair. As noted by Mullaly (2010) “discourse is a framework of thought, meaning, and action, which does not reflect knowledge, reality, or truth, but creates and maintains them" (p. 28). We can see how a discourse of Black hair being "unmanageable" is oppressive and perpetuates racial categories and negative stereotypes. An anti-oppressive approach to practice includes being aware of the languages and ideas within society and deconstruct them to promote equality (Mullaly, 2010), and that can include understanding how some approaches to Black hair care by child protection workers are oppressive.

Hair should be a learning experience for foster parents. Daniel (2011) highlights that "for some foster parents, they were intrigued by the emphasis some Black children placed on their hair" (p. 2235). Daniel (2011) highlighted that the foster parents "could not believe how time consuming and highly valued hair was to some black children" (Daniel, 2011, p. 2235). "In the African Diaspora, hair is even more important than skin color, language, or religion because it serves as a critical marker of race and group identity" (Rosado, 2008, p. 61). This negative discourse continues to maintain stereotypes about good hair versus bad hair.

"Because of the variety of hair textures and choice of styles among African Americans, several additional skills must be learned if mothers are to perform the task of combing their children's hair adequately" (Lewis, 1999, p. 510). There are different types of techniques to braid 
a child's hair, hair treatments and hot combs used, which are very minimal skills to have to maintain a child's hair grooming (Lewis, 1999). "Beads, ribbons, and other types of adornments provide mothers with opportunities to show off their particular skills and contribute to the children's pride and self-esteem" (Lewis, 1999, p. 510). “Certain additional skills requiring maternal sensitivity have been demonstrated to contribute to children's feelings of security" (Lewis, 1999, p. 510). This is also a learning opportunity for children to continue their cultural tradition.

\section{Training}

Caucasian foster families find it difficult to do Black children's hair, as a participant mentioned. Robinson (2011) highlighted that different type of hair textures can be difficult to manage, comb and style (e.g., kinky hair texture), although noting that the kinkiness allows for diverse hairstyles. The unmanageability of a child's hair by Caucasians, can make a child have negative feelings about their own hair. The literature acknowledges the lack of cultural identifying training provided to foster parents, which is also mentioned by the participants. "Foster parent training usually includes information on foster children's typical backgrounds of abuse and/or neglect and how abuse and neglect influence their behavior and development" (Coakley \& Buehler, 2008, p. 410). Foster parents are also trained on attachment and separation (Coakley \& Buehler, 2008). Also “they are educated on the importance of preserving children's family identities and histories, which involves maintaining contacts between the children and their families and communities" (Coakley \& Buehler, 2008, p. 410). The training primarily focuses on the foster parent's contribution to the child's identity. (Coakley \& Buehler, 2008). While all these factors are important, it seems that foster parents are not given practical day to day training on a child's needs, such as Black hair care. 
While the participant handed me the pamphlet, it was explained that a past Black worker had written it. It is interesting to note that a Black worker within the organization had to develop guidelines to educate a white centred organization. Within the social work field, "education and consciousness-raising among clients and co-workers" is important (Baines, 2011, pg. 3). The worker no longer works within the agency, which suggests that the possibility of this pamphlet being available, not continuing, and not having anything to replace it suggests that programming for appropriate hair care is problematic. This is concerning, as it demonstrates that there were no practices and education beforehand. If there was no one to initiate this small act of education, how then would foster parents be able to access this information? The pamphlet used discussed the different textures of Black hair and the products used. Also, it listed a few community hair salons and commonly used products appropriate for Black hair care. However, I am not aware of the year that the pamphlet was written; it has not been updated as there are more products and resources that have emerged recently that were not noted in the pamphlet. This makes me wonder what were the issues happening prior to its development. However, though it has been written by a worker, other departments are not familiar with the pamphlet, illustrating there is no consistent educational practice in the agency. It appears that only workers who work with foster parents who ask for this information are given the pamphlet. Also, since the past worker has left the agency, the pamphlet has not been updated. A suggestion is that the pamphlet once updated be kept as a checklist of documents to be given to the foster parents.

Daniel (2011) believes that child protection agencies should have a more prominent role collaborating with community cultural resources. "Some foster parents suggested having a space, provided by child protection agencies, for them to sit down with the professionals who are the guardians of children to discuss issues related to culture and identity" (Daniel, 2011, p. 2236). 
Based on the interviews, it seems that foster parents are learning through firsthand experiences on their own, rather than having formalized training or guidance from parents on Black hair care.

The research findings from the child protection workers were that foster parents are willing to research and learn on their own. "A second implication involves the need to offer cultural training and services to parents of transracial adoptees" (Padilla et al., 2010, p. 68). There are minimal services for individuals who chose to adopt a racialized child (Padilla et al., 2010). "A survey of 195 public and private adoption agencies that facilitate TRA found that about half of these agencies provide relevant training, and this typically occurs in only one session" (Padilla et al., 2010, p. 68). "Therefore, the cultural development and identity formation of children and youth from racialized groups can be supported throughout transcultural foster care placements, if foster parents seek out and have access to culturally relevant people and resources" (Daniel, 2011, p. 2237). As discussed in the findings section, foster parents engage with community, research online, or connect with other foster parents or family members about this issue.

As noted in the findings, that family relationships are forms of education for foster parents. However, cultural competency or culturally sensitive training is problematic. There are various textbooks on information specific to cultures; however, they are limited in the in depth understanding and complexities of one's culture (Nelson \& McPherson, 2003). From an integrative approach terminology such as ethnic-sensitive practice and cultural competency aid in categorizing individuals which is based on a positivist framework (Nelson \& McPherson, 2003). ““'A social worker practicing from a culturally sensitive or competent approach begins with a defined knowledge based on the culture of the client” (Baines, 2003, p. 90), which can include knowledge from previous experiences with clients from a similar cultural identity. This 
is problematic as every person practices their culture differently, just as there are varying textures, styles and curl patterns of hair which use different products. It is essential that workers learn from their client, as they are the experts of their lives and this will allow workers to be consciously aware as well as being conscious not to further oppress their clients through their practice of cultural competency.

\section{The Hair Community: What is Being Done?}

A research report by the One Vision One Voice Steering Committee, a project of the Toronto CAS discussed varying issues pertaining to the African Canadian population in Ontario. There are varying Societies based in Ontario included in this project. The report highlighted that the Children's Aid Society of Toronto offers a program called Beautiful Hair, Beautiful Me (One Vision One Voice, 2016). The "program provides hair care services and hair care products to African Canadian youth in care, as many are placed with caregivers who are not familiar with the hair care needs of African Canadians" (One Vision One Voice, 2016, p. 49). This illustrates that hair is an issue within the child welfare system and there are changes being made, with discussions being held on a larger scale. The report also shared the importance of educating and supporting foster parents and residential homes on Black children's culture and hair (One Vision One Voice, 2016).

In caring for children and youth from racialized groups, the child welfare field is called upon to initiate a collaborative relationship between foster parents, child protection agencies, biological families and community resources" ... [which include] ... "forming such a collaborative relationship, agencies may draw support and resources from each other to effectively identify and establish relationships with culturally relevant resources, to meet the needs of children and youth from racialized groups (Daniel, 2011, p. 2239). 
To have successful transcultural fostering, child protection workers have to assess carefully foster parents' willingness to participate in a child's cultural development (Coakley \& Buehler, 2008). It is the responsibility of child protection workers to connect with culturally appropriate community resources to be educated on the needs of their clients (Daniel, 2011). Anti-oppressive practitioners are to be aware of service users' social location and intersections, as they contribute to their individual issues (Healy, 2005). The findings suggest that there is a lack of training on community resources; as a result, workers need to take more initiative to learn about different hair needs as they are the service provider.

"Research indicates that there is an under-representation of foster parents from racialized groups and an overrepresentation of children from racialized groups in North American foster care" (Daniel, 2011, p. 2231). The Ontario Child Protection Standards (2016) states that working and developing partnerships with community agencies serving specific cultural or religious groups can also enhance understanding and awareness of the backgrounds of the clients' populations that CASs serve in their communities ... It can also assist CASs in providing culturally appropriate supports to families (p. 14).

Williamson and Gray (2011) highlight the importance of involving the child, biological parents, foster parents and other family members to work in partnership with other community organizations. "Agencies and practitioners are encouraged to view family members as experts and equal partners in caring for their children" (Williamson \& Gray, 2011, p. 1212). In the findings, workers noted the importance of integrating parents in making decisions about culture and hair needs. This illustrates that parents are seen as experts and still have a duty to maintain the connection with their children though they may not be in their care. 
"For many African Americans, hair is inter-generationally meaningful and may be a powerful vehicle for intervention and connection" (Ashley \& Brown, 2015, p. 599). Foster parents who are caring for any hair type need to recognize it as a skill that one has to learn. "Similar to going to a doctor to discuss her daughter's skin, one can go to a beauty parlor, consult outside sources (e.g., books, magazines, or the Internet), or ask others about caring for different hair textures" (Sweeney, 2013, p. 50). During the interview, the participants mentioned places to access hair products such as Walmart; however as Black female I can attest to the fact that Walmart has a small selection of products for Black individuals. In fact, most major cities have beauty supply stores that cater to Black hair care. It is concerning that the participants were not aware of this point.

Child protection workers should have available contact information to resources within the community. Ultimately, a policy should be implemented that requires social workers to schedule appointments, or establish contact with culturally relevant resources, for children and youth from racialized groups in foster care (Daniel, 2011). When child protection workers are required to make decisions in the best interest of children due to policies, it is important they support children culturally within a foster home (Daniel, 2011). This includes access to resources for hair care.

While parents, foster parents and child protection workers play a role in hair care maintenance, so too does the child. Children also have responsibilities for their hair. Children are encouraged to save their allowances for more expensive hairstyles and maintenance. Yet, if a child would like a hairstyle, they have limited authority to make choices, as their parents have to approve of this. It would be interesting to understand how much money children and youth are paid in allowances, as well how much funding they are provided with for their hair care 
maintenance. This illustrates the lack of a voice that children have in their daily needs, as the 'adults' make all the decisions concerning their well-being. However, more children within the Canadian child welfare system are speaking out as illustrated in news articles stated above, which is important as they are the ones interacting with the system and are being serviced by it.

There are many institutional and structural changes that need to happen for progress to occur. Daniel (2011) suggests that "in both remote and urban communities, social workers should also be required to provide in-home resources to foster parents and children and youth from racialized groups in their care" (p. 2239). Supporting these changes is part of a social worker's role, as Healy (2005) notes that “at an institutional level, anti-oppressive social workers promote changes to the organization and delivery of services in ways that enhance antioppressive practice and service user control” (p. 185). Child protection workers can be more engaging politically and socially to adhere to social work principles of providing equitable services to meet one's basic needs (Hoefer, 2012).

"The questions that dominate the discussion on the absence of racial minorities in the cultural fabric of Canadian society- who gets to make decisions about what issues- are also part of the 'access to services' discussion" (James, 1996, p. 185). "The composition of the staff and board of a service agency is a critical factor in determining the vision and the corporate culture of an organization" (James, 1996, p. 185). Recall the Black worker at the agency, who was able to educate her fellow colleagues on cultural aspects pertaining to Black children's skin and hair. James (1996) suggests

If community voices are not represented and heard, then policies, procedures, structures, and modes of service delivery, based and developed on a narrow set of views, 
experiences, and assumptions, will meet the needs of some and automatically (and often unintentionally) exclude others (p. 185).

As well, "their voices must be part of every program, policy, planning effort and evaluation" (Baines, 2011, p. 7). Given that many child protection workers are white, and that there does not appears to be strong representation from the Black community on committees, we can see how Black hair care, and other needs of Black children in care, may get ignored or insufficiently addressed. The child welfare system also needs to hear from Black children and youth about what matters to them when they are in care. "Transformation lies in remedies formulated by service users- it lies in social work giving up speaking about what child welfare "clients" need and listening to what service users themselves say they need" (Dumbrill, 2003, p. 101).

The findings demonstrate that there is a lack of consistency regarding hair practices and training for workers, foster parents, group homes and outside paid resources. The participants noted the lack of training on all levels of staffing (e.g. social workers, foster parents) with respect to Black hair care. It seems that each person learns through personal experience depending on the child or youth on their caseload. As well, the Society does not know the training that group home workers have which is problematic, as they have Black children in their care. Furthermore, the child may be missing out on the opportunity for further attachment and nurturing through acts such as hair combing. However, though limited, there is some work being done by One Vision One Voice and the media are making communities more aware. 


\section{Chapter VII: Implications and Conclusion}

This research explored child protection workers and their experiences working with Black youth's hair. Through a narrative approach, the challenges and positive experiences workers encountered provided insight into current issues and future opportunities for change within the structures of child welfare. While there are strengths within the research which provided insightful information, there were limitations encountered throughout the process as discussed below. This chapter ends with a discussion of future research and implications for social work.

\section{Limitations and Strengths}

The research provided a better understanding of the limited education and resources within agencies regarding Black youth and their hair. It was the goal of this MRP to understand the experiences of child protection workers providing hair care to Black youth in care. Though this was a small sample size of participants, they shared interesting dynamics that happen within a family and the system. Through the narrative approach, I was able to learn from each participant's personal experience working with Black youth.

However, there are limitations of this study which include the time frame, sample size, lack of prior research and the interview guide. The time frame of the MRP process did not allow for time to have more participants in the study. As a result, the sample size is small with three workers. Also, the participants are all from the same agency, but being from different departments did help in providing diverse perspectives. However, I did not have a broader understanding of the challenges and experiences in other agencies in Ontario. Also, the length of interviews were short which limited the amount of information provided. Further probing of information may have provided more in-depth understandings of the child welfare system, the 
clients and the workers. The interview guide was limiting, as it was created many months prior to the interviews occurring. There were questions that I wanted to explore as the research unfolded, which could have helped workers to elaborate more on their narratives. Lastly, there could have been biases in the information that the workers presented. As I am a Black female, asking white workers about their work with Black clients can be intimidating or judgmental. Despite the limitations of this study, I was able to garner some knowledge about the issue of hair care for Black children and youth in care, and develop some suggestions for future research to explore.

\section{Future Research}

Although the research presented pertinent information about the lack of hair resources and the responsibilities that each person has in the child welfare system, there is still future research that could be incorporated. Future research could include workers from many agencies, and, more diversity of the identities of workers, which could add more complexity and perspective to the issue. Racialized workers may provide a unique perspective, as they may explain the challenges, barriers or advocacy that they do when working with children that look like themselves. Furthermore, in the future, it would be beneficial to expand the study to more child welfare agencies. Understanding variety based on the location of the agency, the services provided and the caseloads would allow for a deeper understanding of child protection workers' experiences. Expanding beyond one agency and drawing on many agencies within Ontario to get better understanding of the issues on a wider scale would be paramount. This would allow one to see similarities or differences between each agency, which allows one to see what can be changed in the child welfare system. Also, exploring how each agency engages with the community and the resources provided in different agencies would be helpful. 
This research provided the perspectives from the workers. For future research, it would be interesting to have the voices of the children in care to understand their experiences around hair care maintenance. Possibly, this can provide the welfare system with ways to improve their services or better understand children's cultural needs. Such research also can provide insight into the challenges encountered in a worker-client relationship. The biological parents' voices would also be meaningful for future research, as they have some authority in regard to the basic needs of their children. The parents or guardian can have opinions on how they feel their children's cultural needs are being met outside of their care. Moreover, biological parents or guardians could contribute in discussions about attachment through hair combing at visits, if they are provided with options to do their children's hair and the communication with foster parents can be further explored. The questions to further consider are what if parents are not opened to sharing their practices? Are foster parents monitored if the correct hair care is being used? Since foster parents have a major part to play in Black children's lives, it would be important to further consider their participation in research.

A training for all foster parents from a culturally appropriate member in the community, would provide answers for any questions that may be had. This will relieve foster parents and child protection workers from having to seek different community members on their own. Consistency is important from both child protection workers and foster parents. Black children and youth need their hair maintained, as it cultivates their identity. The age of a child also has an effect on their hair care maintenance, as older children can express or do their hair how they would like. This is an important factor for training.

Through this research, I have gained more understanding of the systemic and individual challenges that child protection workers face, as they have to keep in mind the best interest of the 
child, while incorporating the agency policies and caregiver's requests for their children. There needs to be more interaction between the agency and culturally relevant community organizations. Through continued learning, workers will learn how to better assist their clients around their hair care needs. It is important to train all individuals involved about not only how to deal with trauma, but to include simple day to day needs such as hair.

\section{Implications}

The child welfare system is going through significant changes, around issues such as race. It is the hope that this hairy situation will be more of a topic of conversation and changes will be made within the system and larger structures. Anti-oppressive practice (AOP) is about learning new knowledges and practices (Baines, 2011). "AOP is constantly refining its theory and practice to address new tensions and social problems, as well as underlying structural factors" (Baines, 2011, p. 4). While hair may be an individual or group specific identity, there are many macro-level institutions that have an effect at the individual level. Large institutions such as capitalism, government policies, cultural institutions, social and financial policies play a role in a Black child's hair (Baines, 2011). Also at a micro-level, day to day practices, societal norms and policies within the work place can generate oppression (Baines, 2011). "Antioppressive social workers try to provide service to people seeking it, but also they help clients, communities, and themselves to understand that their problems are linked to social inequality" (Baines, 2011, p. 4).

There are Black youth across Ontario as part of the child welfare system. There needs to be some guide for child protection workers around cultural practices. "Social work must join with other groups to organize and mobilize people to make larger-scale, transformative changes" (Baines, 2011, p. 7). While there are workers who would like to make changes, it becomes 
difficult as child welfare organizations are funded by the government. As a result, workers have policies and laws to abide by which reflect dominant ideals, which creates complexity with a child protection role (Baines, 2011). "The notion of the state as a constantly changing, unstable equilibrium of struggles and counter-struggles permits AOP social workers to recognize that there are spaces in this instability in which to resist oppression and to build new practices, relations, and solidarity with others doing likewise" (Baines, 2011, p. 17).

It is important that parent and worker have a shared purpose and communicate effectively about the child (Baines, 2011). Child welfare is about the protection and best interest of the child, with a focus on issues around abuse, neglect and so forth. While these are important issues to work on with the alleged family, cultural aspects need to be included to maintain some normalcy in a child's life. Workers have large caseloads which does not allow them the time to dedicate to each child on a holistic level to meet their needs (Yamatani et al., 2009). Also, in a field such as child welfare with a high turnover rate, training is necessary as there are differing people within the client's life. Yet, a cultural competence focus on racial and ethnic differences, for example, may convey misconceptions that racial and ethnic groups can be understood as a set of observable and predictable traits, thereby instilling a false sense of confidence in workers about their knowledge of culturally different individuals or families (Ortega \& Faller, 2011, pg. 29). Furthermore, "another aspect about negative social construction is that it does not allow for the hegemonic group to learn about 'The Other' since that would be an oxymoron, resulting in a total ignorance about 'The Other' hence the stereotypes" (Miller, 2016, p. 86). However, while these critique about cultural competence are important, it is also paramount that workers build the knowledge they need to provide service and have rapport with their clients. 
This research provided a starting point for further research to delve deeper into this hairy situation. Through the research, it is illustrated that there needs to be more community collaboration, especially regarding different racialized groups. An agency such as the Children's Aid Society should not work in silos, as the agency is continuing to increase in servicing children from Black and Indigenous communities. An anti-oppressive practice requires personal practice and structural changes to appropriately meet the needs of Black children. While hair is a physical trait, it encompasses issues pertaining to racism which continues to be an issue in Canada and around the world. 


\section{APPENDIX A}

RYERSON

UNIVERSITY

\section{Consent Form}

You are being invited to participate in a research study. Please read this consent form so that you understand what your participation will involve. Before you consent to participate, please ask any questions to be sure you understand what your participation will involve.

A Hairy Situation: Social workers' experiences providing hair care to African Canadian children in care.

Investigators: This research study is being conducted by Chantal Gray, Masters of Social Work student at Ryerson University. Supervisor is Susan Preston from the School of Social Work at Ryerson University.

If you have any questions or concerns about the research, please feel free to contact Chantal at chantal.gray@ryerson.ca

Purpose of the study: The study is meant to explore and evaluate the experiences of social worker's capacity to care for black children and youth hair. The criteria for this study includes individuals who are social workers, and who work with black children and youth in child welfare services. I will interview 3-5 participants. I am conducting this research as a graduate student in partial completion of my degree. The results of the research will contribute to my major research paper and future research.

What Participation Means: If you volunteer to participate in this study, you will be asked to do the following things: share your experiences through an interview about working with black children and youth and how hair care is provided for them. This will be done by face to face interviews, which will be audio recorded wherever you are comfortable to meet. The interview will be about one hour for a single session. The interview questions will be semi-structured, open ended in which you have the option to answer or not. These are a few of the questions that will be asked in the interview. They are: what happens to a child that comes into care and is not able to care for their own hair? What hair care resources are in place? As a participant, you have two weeks to withdraw after the interview, however after the data analysis has begun you can no longer withdraw.

Potential Benefits: The research may bring light to the limited hair resources that social workers have in regard to caring for black children in care. This may contribute to current knowledge about the issues facing black children and youth in care. There are no anticipated direct potential benefits to participants. However, the information shared will help in implementing appropriate hair care for the children. 
What are the Potential Risks to you as a Participant: The potential risks are low, however there are psychological risk such as participants feeling discomfort from the questions being asked about particular practices or experiences. However, if you feel uncomfortable, you may skip answering a question or stop participation, either temporarily or permanently. The social and financial risks are that social workers may feel exposed for not appropriately serving the needs of the children in their care which could affect their employment. This risk can be mitigated by keeping names and work affiliation confidential. Also, participants can state if they would like certain information removed from the research. The personal identity of participants will be kept confidential through the use of pseudonyms and using general descriptors. Furthermore, if a participant shares stories about a child being harmed, I will have a duty to report. There is also a dual-role risk, as I am currently completing my practicum at a Children's Aid Society. Thus, only particular departments in the agency will be interviewed.

Confidentiality: Confidentiality will be maintained through not having identifying markers of your name or place of work. Pseudonyms will be assigned. Furthermore, given that the interview may take place at the Agency, the fact that you have participated is likely to be known to coworkers.

Data which include transcriptions and audio-recordings will be secured and stored safely in a locked cabinet in the researcher's home and will be password protected. If there are concerns disclosed during the interview in regard to a child's safety, there is a duty to report.

Participants will be audio recorded. The recording will be password protected, downloaded, transcribed then deleted immediately.

Data will be kept for seven years according to the Ontario Association of Social Workers. Once the time is up, paper documents will be shredded and electronic files will be deleted.

Incentives for Participation: Participants will not be paid to participate in this study.

Costs to Participation: As a participant, you are entitled to two bus tokens if public transit is used or $\$ 10$ gas card as reimbursement to partake in the research.

\section{Voluntary Participation and Withdrawal:}

Participation in this study is completely voluntary. You can choose whether or not to be in this study. If any question makes you uncomfortable, you are free to skip the question. You may stop participating at any time and you will still be given the reimbursement described above. If you choose to stop participating, you may also choose to not have your data included in the study. Participants can withdraw at any time, before or after the interview. However once, data analysis begins participants are no longer able to withdraw. Your choice of whether or not to participate will not influence future relations with Chantal Gray, Dr. Susan Preston, Ryerson University and the Children's Aid Societies.

Questions about the Study: If you have any questions about the research now, please ask. If you have questions later about the research, you may contact. 
Chantal Gray, Masters of Social Work student, Ryerson University, School of Social Work at chantal.gray@ ryerson.ca or Supervisor, Susan Preston, Ryerson University at susan.preston@ryerson.ca

This study has been reviewed by the Ryerson University Research Ethics Board. If you have questions regarding your rights as a participant in this study please contact:

Research Ethics Board c/o Office of the Vice President, Research and Innovation Ryerson University 350 Victoria Street Toronto, ON M5B 2K3 416-979-5042

$\underline{\text { A Hairy Situation }}$

rebchair@ryerson.ca

\section{CONFIRMATION OF AGREEMENT:}

Your signature below indicates that you have read the information in this agreement and have had a chance to ask any questions you have about the study. Your signature also indicates that you agree to participate in the study and have been told that you can change your mind and withdraw your consent to participate at any time. You have been given a copy of this agreement.

You have been told that by signing this consent agreement you are not giving up any of your legal rights.

Name of Participant (please print)

Signature of Participant Date

I agree to be audio recorded for the purposes of this study. I understand how these recordings will be stored and destroyed.

Signature of Participant Date 


\section{APPENDIX B}

\section{Interview Guide}

1. Do you have African/Black clients? If Yes, how many?

2. Are you aware how to care for a black child's hair?

3. What happens to a child that comes into care and is not able to care for their own hair?

4. What determines where a black child is placed?

5. Who is responsible for providing hair care for black youth?

6. Are the children biological parents or guardian from who they were taken, consulted about the care of the child's hair?

7. Are foster parents, group workers provided with training on how to take care of black children and youth in their care hair?

8. What hair care resources are in place?

9. Where are these hair care resources located? 


\section{PARTICIPANTS NEEDED FOR RESEARCH IN A HAIRY SITUATION: SOCIAL WORKERS EXPERIENCES PROVIDING HAIR CARE TO AFRICAN CANADIAN CHILDREN IN CARE}

Are You:

A Social worker who has worked with black children and youth in child welfare and issues pertaining to hair care?

If you answered yes to the above noted question you are invited to volunteer in this study

You will be asked to participate in an interview, sharing your experiences working with providing hair care for black youth in care. I am conducting this study as a graduate student in social work at Ryerson University. I am seeking 3-5 participants for this study.

Your participation will involve an interview for approximately one hour in a single session.

You will be reimbursed with two transit tokens or a $\$ 10$ gas card to cover your expenses to travel to the interview.

If you are interested in participating in this study or for more information, please contact: Chantal Gray, Masters of Social Work student,

School of Social Work

Email: chantal.gray@ryerson.ca

This research study has been reviewed and approved by the Ryerson University Research Ethics Board 


\section{APPENDIX D}

Recruitment Email

$\mathrm{Hi}$

My name is Chantal Gray. I am a student at Ryerson University in the School of Social Work. I am contacting you to see if you might be interested in participating in a research study.

This research is being done as part of my Masters project and my supervisor's name is Professor Susan Preston. The focus of the research is to explore the experiences of social workers providing hair care for black children and youth in care.

To participate you need to be a social worker who has worked or working with black children and youth in child welfare and issues pertaining to hair care.

If you agree to volunteer you will be asked to participate in an one hour interview for a single session.

In appreciation of your time, you will be reimbursed with a transit token or $\$ 10$ gas card.

Your participation is completely voluntary and if you choose not to participate it will not impact our relationship or your relationship with Ryerson University.

The research has been reviewed and approved by the Ryerson University Research Ethics Board.

If you are interested in more information about the study or would like to volunteer, please reply to this email at chantal.gray@ryerson.ca.
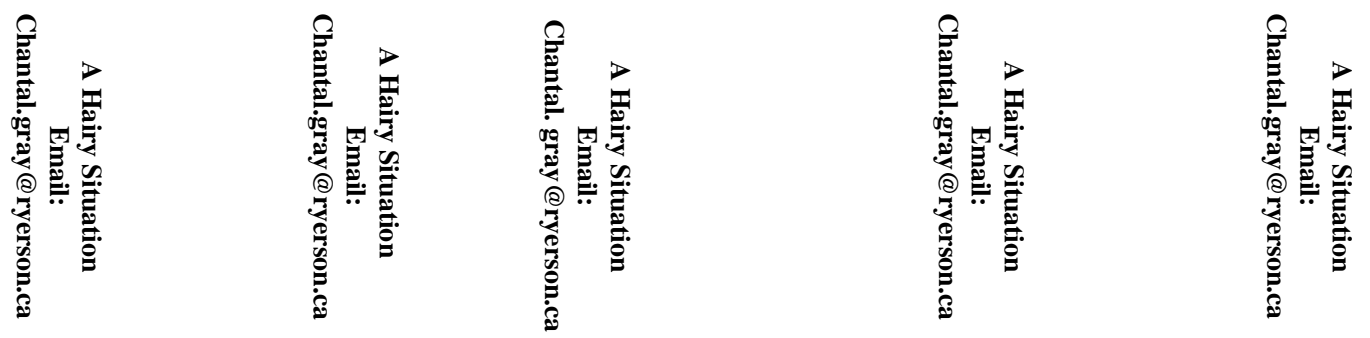


\section{References}

Ashley, W., \& Brown, J. C. (2015). Attachment tHAIRapy: A culturally relevant treatment paradigm for African American foster youth. Journal of Black Studies, 46(6), 587-604.

Aylward, C. A. (1999). Canadian critical race theory: Racism and the law. Halifax, NS: Fernwood.

Baines, D. (2003). Race, class, and gender in the everyday talk of social workers: The ways we limit the possibilities for radical practice. In W. Shera (Ed.), Emerging perspectives on anti-oppressive practice (pp. 43-64). Toronto, ON: Canadian Scholars' Press.

Baines, D. (2011). An overview of anti-oppressive practice: Roots, theory, tensions. In D. Baines (Ed.), Doing anti-oppressive practice: Social justice social work (2nd ed., pp. 1-23). Halifax, NS: Fernwood Publishing.

Brooks, W. M., \& McNair, J. C. (2015). “Combing” through representations of black girls' hair in African American children's literature. Children's Literature in Education, 46(3), 296307.

Brown, N. (2014). "It's more than hair...that's why you should care": The politics of appearance for Black women state legislators. Politics, Groups, and Identities, 2(3), 295-312.

Byrd, A. D., \& Tharps, L. L. (2014). Hair Story: Untangling the roots of black hair in America. New York, NY: St. Martin's Press.

Chand, A. (2000). The over-representation of black children in the child protection system: possible causes, consequences and solutions. Child and Family Social Work, 5(1), 67-78.

Clarke, J. (2011). The challenges of child welfare involvement for Afro-Caribbean families in Toronto. Children and Youth Services Review, 33(2), 274-283. 
Coakley, T. M. \& Buehler, C. (2008). Toward a theory of cultural competence in transcultural parenting: The role of cultural receptivity. Journal of Public Child Welfare, 2(4). 401425.

Constance-Huggins, M. (2012). Critical race theory in social work education: A framework for addressing racial disparities. Critical Social Work, 13(2).

Contenta, S., Monsebraaten, L., \& Rankin, J. (2014, December 11). Taking steps to help black youth in CAS. Toronto Star.

Creswell, J. W., \& Poth, C. H. (2017). Qualitative inquiry and research design: Choosing among five approaches (4th ed.). Los Angeles, CA: SAGE Publications, Inc.

Daniel, E. (2011). Fostering cultural development: Foster parents' perspectives. Children and Youth Services Review, 33, 2230-2240.

Dumbrill, G. C. (2003). Child welfare: AOP's nemesis?. In W. Shera (Ed.), Emerging perspectives on anti-oppressive practice (pp. 101-119). Toronto, ON: Canadian Scholars' Press.

Ellington, T. N. (2015). Social networking sites: A support system for African-American women wearing natural hair. International Journal of Fashion Design, Technology and Education, 8(1), 21-29.

Ellis-Hervey, N., Doss, A., Davis, D., Nicks, R., \& Araiza, P. (2016). African American personal presentation: Psychology of hair and self-perception. Journal of Black Studies, 47(8), 869882.

Everett, J. E. (2004). Understanding African American families and children. In J. E. Everett, S. P. Chipungu, \& B. R. Leashore (Eds.), Child welfare revisited: An Africentric perspective (pp. 89-92). New Brunswick, NJ: Rutgers University Press. 
Font, S. A. (2013). Service referral patterns among black and white families involved with child protective services. Journal of Public Child Welfare, 7, 370-391.

Government of Ontario. (1990). Child and family services act (R.S.O. 1990, c.C.11).

Retrieved from https://www.ontario.ca/laws/statute/90c11.

Greene, D. W. (2011). Black women can't have blonde hair...in the workplace. The Journal of Gender, Race, and Justice, 14(2), 405-430.

Guest, G., MacQueen, K.M., \& Namey, E.E. (2012). Applied thematic analysis. Thousand Oaks, CA: Sage Publications, Inc.

Haight, W., Mangelsdorf, S., Tata, L., Szewczyk, M., Black, J., Giorgio, G., \& Schoppe, S.J. (2001). Making visits better: The perspectives of parents, foster parents, and child welfare workers. Child Welfare, 81(2), 173-202.

Healy, K. (2005). Social work theories in context: Creating frameworks for practice. New York, NY: Palgrave Macmillan.

Henry, P. (2000). Caliban's reason: Introducing Afro-Caribbean philosophy. New York, NY: Routledge.

Hoefer, R. (2012). Advocacy practice for social justice (2nd ed.). Chicago, IL: Lyceum Books Inc.

James, C. (1996). Perspectives on racism and the human services sector: A case for change. Toronto, ON: University of Toronto Press.

Johnson, E. (2013). Resistance and empowerment in black women's hair styling. London, UK: Routledge.

Johnson, T. A., \& Bankhead, T. (2014). Hair it is: Examining the experiences of black women with natural hair. Open Journal of Social Sciences, 2, 86-100. 
Larsson, S., \& Sjoblom, Y. (2010). Perspectives on narrative methods in social work research. International Journal of Social Welfare, 19(3), 272-280.

Lewis, M.L. (1999). Hair combing interactions: A new paradigm for research with AfricanAmerican mothers. American Journal of Orthopsychiatry, 69(4), 504-514.

Lietz, C.A. (2008). Implementation of group supervision in child welfare: Findings from Arizona's supervision circle project. Child Welfare, 87(6), 31-48.

Marshall, J. M., \& Haight, W. L. (2014). Understanding racial disproportionality affecting African American youth who cross over from the child welfare to the juvenile justice system: Communication, power, race and social class. Children and Youth Services Review, 42, 82-90.

Maykut, P., \& Morehouse, R. (1994). Beginning qualitative research: A philosophic and practical guide. Bristol, PA: The Falmer Press.

Metro Canada. (2016, October 25). Black foster youth reclaim their voice. Metro Canada. McRoy, R., \& Griffen, A. (2012). Transracial adoption policies and practices. Adoption \& Fostering, 36(3-4), 38-49.

Miller, C.H. (2016). Uncovering the kink celebrating my black identity: Perceptions on AfroCosta Ricans natural hair. Journal of Arts and Humanities, 5(5), 78-95.

Ministry of Children and Youth Services. (2016). Ontario child protection standards. Retrieved from http://www.children.gov.on.ca/htdocs/English/documents/childrensaid/ChildProtection-Standards_2016.pdf

Moen, T. (2006). Reflections on the narrative research approach. International Journal of Qualitative Methods, 5(4), 56-69. 
Mullaly, B. (2010). Theoretical and conceptual considerations. In Challenging oppressions and confronting privilege (2nd ed., pp. 1-33).Don Mills, ON: Oxford University Press.

Nelson, C. H., \& McPherson, D.H. (2003). Cultural diversity in social work practice: Where are we now and what are the challenges in addressing issues of justice and oppression? In W. Shera (Ed.), Emerging perspectives on anti-oppressive practice (pp. 81-98). Toronto, ON: Canadian Scholars' Press.

Nesmith, A., Patton, R., Christophersen, K., \& Smart, C. (2017). Promoting quality parent-child visits: The power of the parent-foster parent relationship: Foster care visitation. Child \& Family Social Work, 22(1), 246-255.

One vision One voice. (2016, September). Practice framework part 1: Research report. Retrieved from http://www.oacas.org/wp-content/uploads/2016/09/One-Vision-OneVoice-Part-1_digital_english.pdf.

Ortega, R. M., \& Faller, K. C. (2011). Training child welfare workers from an intersectional cultural humility perspective: A paradigm shift. Child Welfare, 90(5), 27-49.

Oyedemi, T. (2016). Beauty as violence: 'Beautiful' hair and the cultural violence of identity erasure. Social Identities, 22(5), 537-553.

Padilla, J. B., Vargas, J. H., \& Chavez, H. L. (2010). Influence of age on transracial foster adoptions and its relation to ethnic identity development. Adoption Quarterly, 13, 50-73.

Patton, T. O. (2006). Hey girl, am I more than my hair?: African American women and their struggles with beauty, body image, and hair. National Women's Studies Association Journal, 18(2), 24-51.

Pon, G. (2009). Cultural competency as new racism: An ontology of forgetting. Journal of Progressive Human Services, 20, 59-71. 
Prince, A. (2009). The politics of black women's hair. London, ON: Insomniac Press.

Robinson, C.L. (2011). Hair as race: Why "good hair" may be bad for black females. The Howard Journal of Communication, 22, 358-376.

Rosado, S. D. (2003). No nubian knots or nappy locks: Discussing the politics of hair among women of African decent in the diaspora. A report on research in progress. Transforming Anthropology, 11(2), 60-63.

Sweeney, K. A. (2013). Race-conscious adoption choices, multiraciality, and color-blind racial ideology: Race and adoption choices. Family Relations, 62(1), 42-57.

Thobani, S. (2007). Exalted subjects: Studies in the making of race and nation in Canada. Toronto, ON: University of Toronto Press.

Thoburn, J., Chand, A., \& Procter, J. (2005). Child welfare services for minority ethnic families: The research reviewed. London, UK: Jessica Kingsley Publishers.

Thompson, C. (2009). Black women, beauty and hair as a matter of being. Women Studies, 38(8), 831-856.

Tong, R., \& Botts, T.F. (2017). Feminist thought: A more comprehensive introduction (5th ed.). New York, NY: Westview Press.

Turner III, D. W. (2010). Qualitative interview design: A practical guide for novice investigators. The Qualitative Report, 15(3), 754-760.

Wane, N.N., Deliovsky, K., \& Lawson, E. (2002). Introduction. In N. N. Wane, K. Deliovshy \& E. Lawson (Eds.), Back to the drawing board: African Canadian feminism (pp. 13-26). Toronto, ON: Sumach Press.

Weitz, R. (2001). Women and their hair: Seeking power through resistance and accommodation. Gender and Society, 15(5), 667-686. 
Williamson, E., \& Gray, A. (2011). New roles for families in child welfare: Strategies for expanding family involvement beyond the case level. Child and Youth Services Review, $33,1212-1216$.

Yamatani, H., Engel, R., \& Spjeldnes, S. (2009). Child welfare worker caseload: What's just right?. Social Work, 54(4), 361-368.

Yee, J. Y., \& Dumbrill, G. C. (2003). Whiteout: Looking for race in Canadian social work practice. In A. Al-Krenawi \& J. R. Graham (Eds.), Multicultural social work in Canada: Working with diverse ethno-racial communities (pp. 98-121). Don Mills, ON: Oxford University Press. 